\title{
Erwan SOMMERER, Sieyès. Le révolutionnaire et le conservateur
}

Jacques Guilhaumou

\section{(2) OpenEdition}

Journals

Édition électronique

URL : https://journals.openedition.org/ahrf/12179

DOI : $10.4000 /$ ahrf. 12179

ISSN : $1952-403 X$

Éditeur :

Armand Colin, Société des études robespierristes

Édition imprimée

Date de publication : 1 septembre 2011

Pagination : $217-218$

ISBN : 978-2-200-92700-4

ISSN : 0003-4436

Référence électronique

Jacques Guilhaumou, «Erwan sommeren, Sieyès. Le révolutionnaire et le conservateur », Annales historiques de la Révolution française [En ligne], 365 | Juillet-septembre 2011, mis en ligne le 13 décembre 2011, consulté le 23 avril 2022. URL : http://journals.openedition.org/ahrf/12179 ; DOI : https://doi.org/10.4000/ahrf.12179

Ce document a été généré automatiquement le 23 avril 2022

Tous droits réservés 


\title{
Erwan SOMMERER, Sieyès. Le révolutionnaire et le conservateur
}

\author{
Jacques Guilhaumou
}

\section{RÉFÉRENCE}

Erwan SOMMERER, Sieyès. Le révolutionnaire et le conservateur, Paris, Michalon, 2011, 115 p., ISBN 978-2-84186-559-8, $10 €$.

1 Erwan Sommerer, chercheur en sciences politiques et co-responsable du Groupe d'études sieyèsiennes à l'Université de Paris I, nous propose un ouvrage, certes de petite longueur, mais particulièrement dense et novateur sur les aspects à la fois les plus connus et les plus complexes de la nouvelle "science politique " proposée par Sieyès dès 1789. À ce titre, il reprend le corpus des textes imprimés mais il interroge aussi les textes politiques manuscrits récemment édités par Christine Fauré chez Champion, et encore peu commentés.

2 Après une rapide présentation du parcours politique de Sieyès, Erwan Sommerer met d'abord en évidence que «l'œuvre de l'abbé est en prise permanente avec la question de la transition entre la pensée et l'action, ou, en d'autres termes, entre la découverte conjointe du meilleur régime et des moyens de le réaliser " (page 12). C'est là où apparaît la notion centrale d'" art social», en tant que science de la société et du pouvoir, science politique donc. « Art social » signifie aussi science de la rupture avec le présent, « science de ce qui doit être » et non « science de ce qui est ».

Une telle subversion de l'être, - l'ordre positif d'Ancien Régime -, par ce qui doit être, un nouvel ordre constitutionnel révolutionnaire, prend appui sur un concept particulièrement stable dans l'œuvre de Sieyès, celui de nation. Erwan Sommerer propose de l'aborder, d'un texte de Sieyès à l'autre, sous l'angle de la notion de communauté morale, au plus proche du contrat social. Adoptant un point de vue à la fois rationaliste et nominaliste, Sieyès énonce les conditions d'identification de l'individu au corps politique d'abord sur la base d'un préconstruit naturel, l'association 
en tant que réunion des individus au sein d'une même communauté. Puis il est question d'un préréquisit, la qualité ontologique de l'individu, ce qui suppose la prééminence de tout individu sur le collectif, donc la préservation avant tout de l'intérêt personnel. Le mode d'action lié à de telles conditions de la science politique n'est autre que le contrat social, en tant qu'il concrétise la réunion des volontés individuelles, l'engagement mutuel des intérêts communs, avec pour but la réalisation des intérêts personnels. La nation apparaît alors sous une double modalité, morale et instrumentale.

C'est là où Erwan Sommerer propose de considérer la Nation chez Sieyès comme une communauté morale pour désigner l'accord initial des individus, une sorte de substrat moral qui précède l'État, réduit à un instrument au service de l'association. Sieyès se retrouve ainsi au plus loin d'une conception de l'État comme artifice politique au sens de Hobbes.

5

De fait, du De Cive (Le Citoyen), publié en 1642, au Leviathan (1651), Hobbes préconise une "science des vertus" sous la forme d'un art politique qui procède d'une force rhétorique apte à entraîner le citoyen dans une attitude active au regard des vertus dont l'objectif est de lui faire abandonner ses intérêts personnels face à la nécessité d'une communauté des croyances. Ainsi un programme d'actions vertueux permet d'accéder à «la science des vertus", alors même que la "science politique » du législateur promeut l'artifice de la politique avec l'État figuré par le Léviathan. Si la figure du législateur se profile autant chez Hobbes que chez Sieyès, tout autre est, chez Sieyès, le lien de la morale à l'État qu'elle établit. Il ne s'agit point de création politique mais de médiation et de représentation des valeurs naturelles par le seul fait de la reconnaissance du pacte social. La distance représentative entre gouvernants et gouvernés, la distance tout court entre citoyens actifs et citoyens passifs exprime, par un apparent paradoxe, une proximité morale, l'instrument politique étant au service d'une communauté des intérêts individuels et des valeurs communes. Une telle instrumentalisation de la politique suppose " un faire faire », et non un « laisser faire », un corps d'élite investi rationnellement, donc apte, compétent à assurer, dans la division des tâches, le gouvernement des hommes et des choses. Nous sommes certes bien loin d'un régime démocratique, le lien représentatif s'inscrivant, de manière conservatoire, dans la logique rationnelle d'un droit naturel restreint aux limites d'un intérêt commun conçu comme le dénominateur commun et minimal entre les intérêts personnels à sauvegarder.

6 Le libéralisme de Sieyès repose donc bien sur l'existence d'une communauté préalable à la fois rationnelle et morale, une sorte de transcendance naturelle, en résumé « une communauté morale pré-institutionnelle fondée par le contrat social, et en position de surplomb par rapport à la forme de l'état» (page 80) précise de nouveau Erwan Sommerer. C'est pourquoi les institutions, totalement instrumentalisées, sont exclues $\mathrm{du}$ pouvoir constituant. Nous sommes donc aux antipodes d'une conception des institutions civiles présidant à l'esprit social, en tant que conditions de l'existence du contrat social, telle qu'elle a été pensée, puis mise en œuvre de Rousseau aux Jacobins. Seule la Nation détient le pouvoir constituant, ce qui situe le pouvoir constituant hors de toute illimitation et de toute législation: il n'est que l'expression de l'extériorité critique de la Nation à l'ordre positif; il n'intervient que dans des moments constitutionnels précis, et jamais de façon permanente, à l'exemple de la révolution permanente récusée par Sieyès. 
7 Cet ouvrage remet ainsi particulièrement bien au centre du débat la question de la nature du libéralisme de Sieyès. À notre avis, il tend à prouver qu'il ne s'agit ni d'un libéralisme politique, ni d'un libéralisme économique. Alors comment le qualifier? Telle est la difficulté majeure de la présente réflexion, nous semble-t-il.

Erwan Sommerer explore, en ce sens, à la fin de l'ouvrage, le parcours "postrévolutionnaire » de l'an III à l'an VIII de la pensée politico-constitutionnelle de Sieyès, son mouvement propre et ses contradictions visibles. Il montre que sa doctrine politique ne cesse de renforcer ses prémisses libérales tout en accentuant son caractère anti-démocratique, son conservatisme donc, ce qui a été également souligné par d'autres commentateurs. Mais reste encore une fois à préciser ce qu'il en est de cette persistance d'une logique libérale de nature révolutionnaire.

Bien sûr, il s'agit de maintenir un substrat moral, initialement présent sous la marque du contrat social, mais au sein d'un mouvement d'épuisement progressif de la critique de l'ordre positif. Le devoir être du pouvoir constituant doit épuiser les possibles et non les ouvrir en permanence. On ne peut donc pas parler d'un libéralisme constituant ou d'un libéralisme critique, qui maintiendrait la nation en position d'extériorité de façon permanente, ce qui restreint encore d'autant la désignation d'un tel libéralisme. Ainsi, soit Sieyès demeure une relative énigme en matière de libéralisme, soit sa doctrine est tout à fait transparente dans le contexte dominant actuel du "faire faire " d'un libéralisme expert, donc profondément élitiste. Optons pour la première solution pour laisser au chercheur, comme le fait si bien Erwan Sommerer, le soin d'en débattre sur la base d'une (re)lecture conjointe des textes imprimés et manuscrits. 